Military Technical College Kobry El-Kobbah, Cairo, Egypt

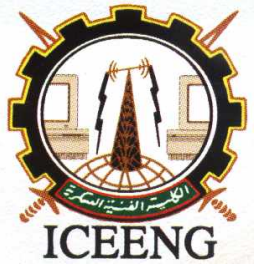

$6^{\text {th }}$ International Conference on Electrical Engineering ICEENG 2008

\title{
Identification of the Most Effective Supplementary Signal in Damping a Particular Power System Mode of Instability
}

\author{
By
}

A.A.ISHAK*

\section{$\underline{\text { Abstract: }}$}

Previous works in the field of power system stability adopting the concept of supplementary signal were mostly dedicated to stabilize all system modal instabilities. In this paper a study is made to identify the particular type of supplementary signal most-effective in increasing the damping introduced to the excitation system over a specific power system mode of instability. To this end, a series of MATLAB algorithms were developed and the results obtained yielded a set of supplementary signals to be introduced to the excitation of a single machine infinite bus-bar power system. The effect on increasing damping over a particular system mode is evaluated. The outcomes from extensive case studies confirmed the validity of the proposed approach.

\section{Keywords:}

Supplementary signal, modal interaction, power system stability, signal processing.

* Faculty of Engineering (shoubra), Benha University, Egypt 


\section{Introduction:}

In the past two decades, numerous approaches were directed towards using supplementary signals derived either directly or indirectly from the machine state variables for the purpose of enhancing the system modal damping introduced by the voltage control loop during transient periods [1-5]. Power system instability can take one of several forms such as mechanical instability (hunting mode), electrical instability (self excited oscillation) and electromechanical instability (subsynchronous resonance); as well as other forms [6-10].

Classification of supplementary signals can be listed as follows: derivatives of machine terminal voltage, machine rotor current and/or its derivatives, machine active power $\mathrm{P}$ or machine reactive power $\mathrm{Q}$ and their derivatives and finally machine rotor angular speed deviation $\omega$ and its derivative signal $(\Delta \omega)$ [11,12]. The latter is known as power system stabilizer, PSS, and is the one most widely used to increase the effectiveness of the AVR in controlling power system instability. The outcomes of such approaches remain restricted by the exciter and machine field constraints [13].

This work presents a comprehensive computational study, carried out using a set of MATLAB algorithms, to evaluate and assess the effect of the above mentioned supplementary signals in enhancing the effectiveness of the control loop in damping out modal instabilities which may occur in power systems. The study addresses each supplementary signal as linked to a specific type of modal instability. This is achieved through three basic measures namely:

1. Selecting the appropriate supplementary signal to modulate the response of the AVR for the effective control of the selected form of instability.

2. Devising a signal processing strategy to blend the selected supplementary signal to be fed with the existing control system to achieve an inphase signal reinforcement.

3. Tuning the controller parameter, through optimization algorithms, to best suite suppressing the actual form of instability.

\section{Problem Formulation:}

In addition to the system power frequency, generated under steady normal operation, other unwanted oscillations may arise due to changes in system configuration or switching causing stability problems [6,7]. The modes of instability in power systems are usually manifested in two basic forms:

Instability with monotonic nature; which may occur due to unbalance either through power surplus or deficiency between generation and delivery. 
Instability with oscillatory nature; caused by the exchange of energy between either like or unlike energy forms i.e. electrical to electrical exchange or electrical to mechanical exchange etc.... The range of frequency of oscillation can fall into two major domains: the first domain of oscillation resides in the supersynchronous zone where all modal interactions falling into this domain are well damped and do not provoke stability problems [14]. On the other hand the second domain of oscillation is of subsynchronous nature and can be subdivided into self excited oscillation, subsynchronous resonance, hunting mode and inter-area oscillations etc.......and may cause stability problem and even damage of system components. In this domain ultra low range of subsynchronous oscillation where very low subsynchronous frequency are encountered, with frequency ranging below $1 \mathrm{~Hz}$ and is attributed to the instability due to rotor masses oscillating in unison against the mass of the infinite system or due to the inter-area oscillation between two large pools of energy connected through a relatively weak tie line. Here, although the magnitude of these oscillations may not be of pronounced nature, yet they are poorly damped causing the oscillations to become persistent [15].

Attention in this paper will be basically focussed on selecting the most effective signal, altogether with defining the feeding methodology the feeding methodology of this signal to the voltage control loop augmented by the optimal tuning of the controller parameters to achieve the suppression and control over a given unstable mode.

\section{Systems under Study}

Three basic power system configurations were selected to generate the modes of instability and to test the suggested approach for effective control are listed as follows:

1. A single machine connected to an infinite system through a step up transformer and a tie line as shown in fig.(1) to model for the machine power angle instability.

2. A single machine connected to an infinite system through a step up transformer and a series compensated tie line as shown in fig.(2) to exemplify for the problem of self excited oscillation .

3. A single machine with a multimass rotor representation is connected to an infinite system through a step up transformer and series compensated tie line as shown in fig.(3) to provoke the subsynchronous resonance phenomena and test the proposed suppression approach.

The study routine will be performed testing various supplementary signals when system is undergoing either a small perturbation or a large scale disturbance and the results presented in this paper are the ones that has yielded best damping and thus the ones that can reduce the probability of system instability and enhance stability limit to its utmost level. 


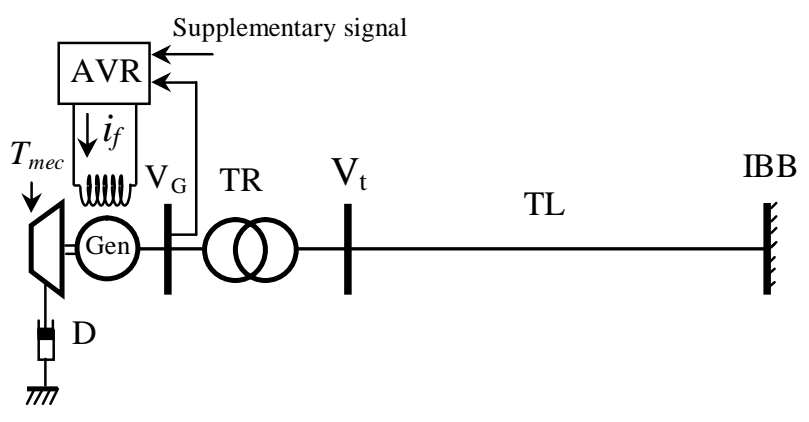

Fig.(1) System A Single machine infinite bus bar

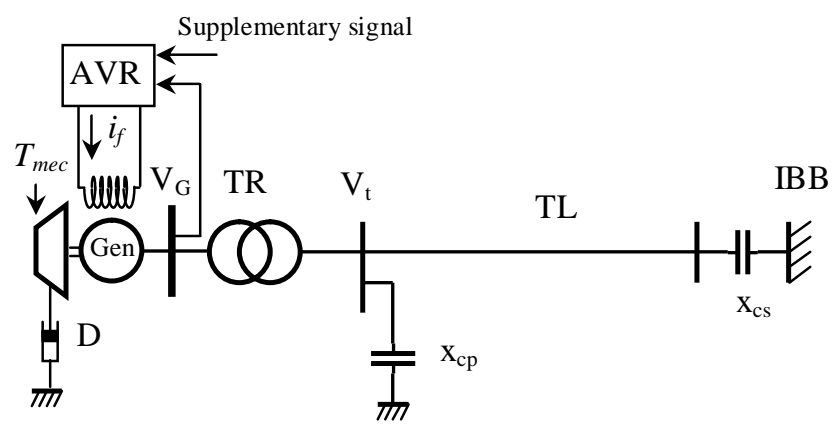

Fig.(2) System B Single machine infinite bus bar with compensated tie line

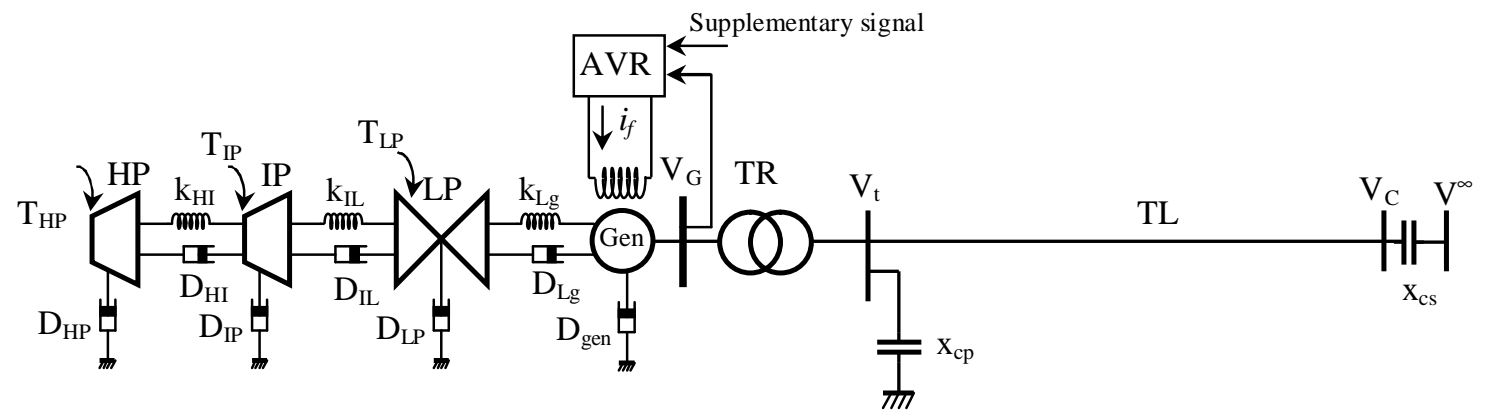

Fig.(3) System C Single machine infinite bus with multimass shaft representation and compensated tie line

\section{Selection and Conditioning of the Supplementary Signal(Expanding the Power Angle Stability Limit)}

In this study the fast acting static exciter (thyristor based) model is adopted and the block diagram representation for this model is shown in fig.(4) $[13,16]$. All generating units equipped with such excitation system, necessitate supplementary stabilizing signals to suppress the mechanical oscillations. Here the stabilizing signal is derived from rotor angular speed deviation (PSS); needless to say that PSS must provide enough phase compensation over the expected range of oscillation frequencies. For design purposes of conventional power system stabilizer (CPSS), its transfer function is in the form of:

$$
\mathbf{G}_{\mathrm{PSS}}(\mathrm{s})=\mathbf{K}_{\mathrm{PSS}}\left(\frac{1+\mathrm{s} \mathbf{T}_{1}}{1+\mathrm{s} \mathbf{T}_{2}}\right)^{\mathrm{k}}
$$

where $\mathrm{k}$ denotes the number of phase compensation blocks and $\mathrm{T}_{1}, \mathrm{~T}_{2}$ are the time constants that must be set to provide damping over the range of frequencies at which oscillations might occur. System parameters and controller are given in Appendix A. 


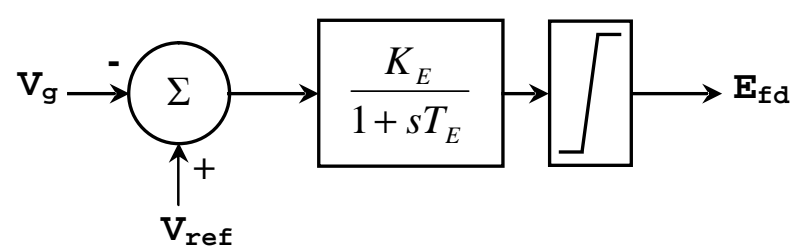

Fig.(4) Type IV automatic voltage regulator (AVR)

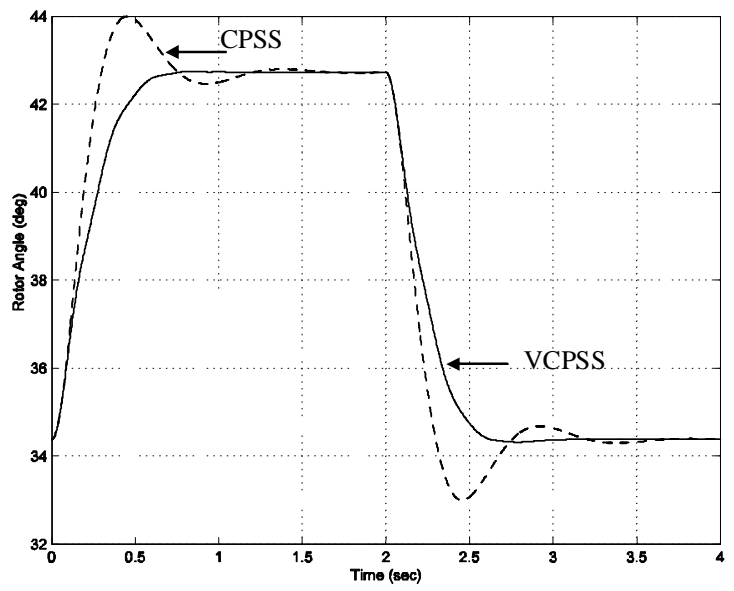

(a)

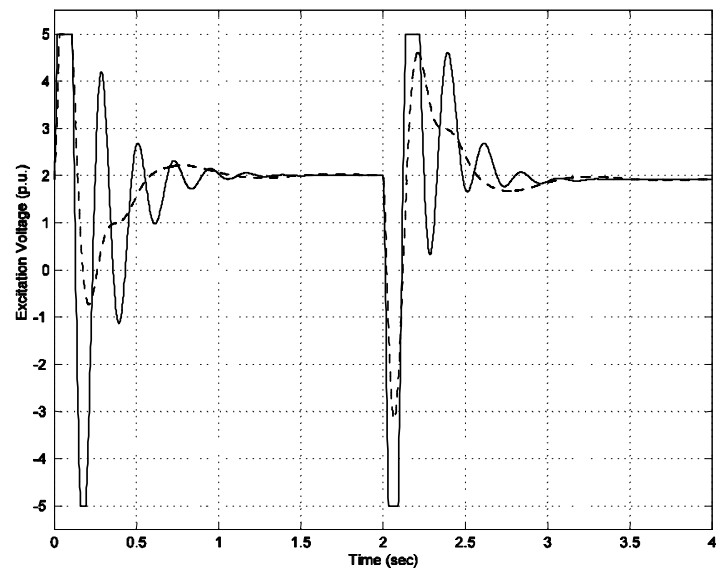

(b)

Fig.(6) Time variation in rotor power angle(a) and excitation voltage $(b)$ due to a $10 \%$ increase in $T_{\text {mech }}$; with full recovery after $2 \mathrm{sec}$

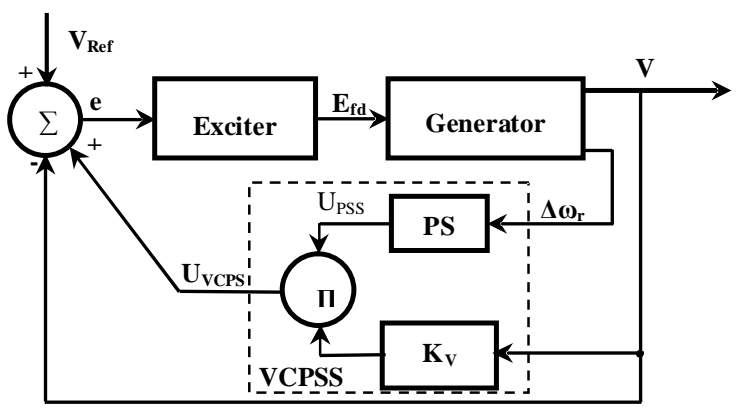

Fig.(5) Voltage controlled PSS stabilizer (VCPSS)

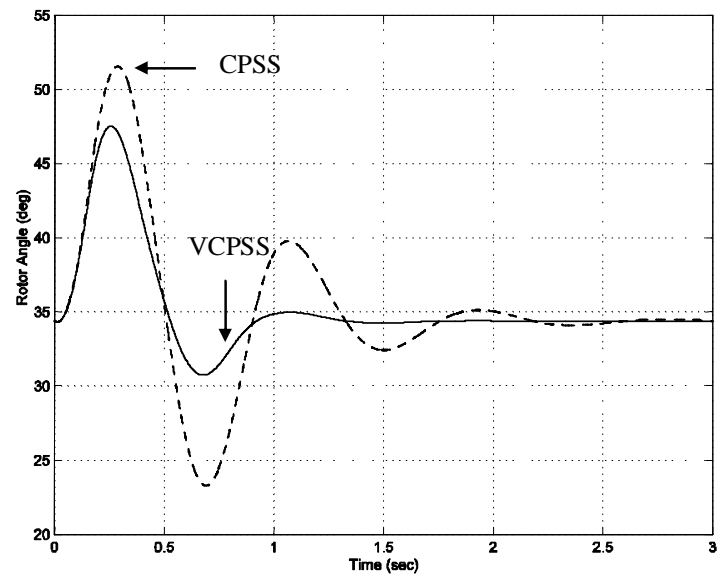

(a)

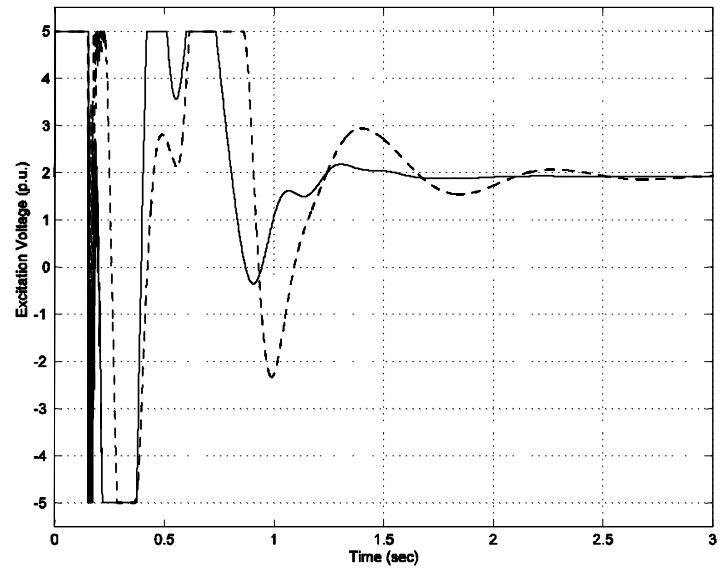

(b)

Fig.(7) Time variation in rotor power angle (a) and excitation voltage $(b)$ due to a three-phase short circuit at the HT terminals of the power transformer with system restored after a $150 \mathrm{msec}$ 
In fig.(5) the block diagram of a voltage controlled PSS stabilizer where the machine voltage is engaged with the supplementary signal to produce a signal $\mathrm{U}_{\mathrm{VCPSS}}$ that will provoke the exciter response immediately after the occurrence of a disturbance as it can be seen from the excitation response shown in fig.(6) and fig.(7).

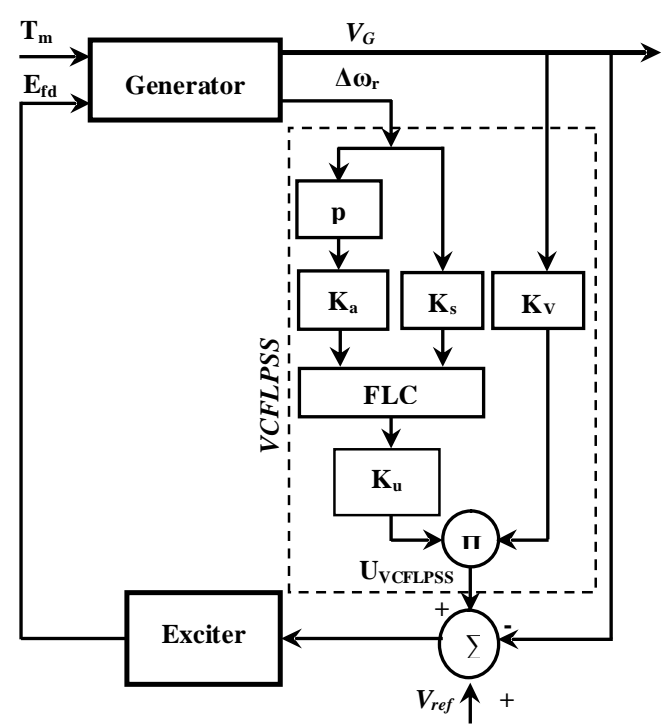

Fig.(8) Block diagram for VCFLPSS

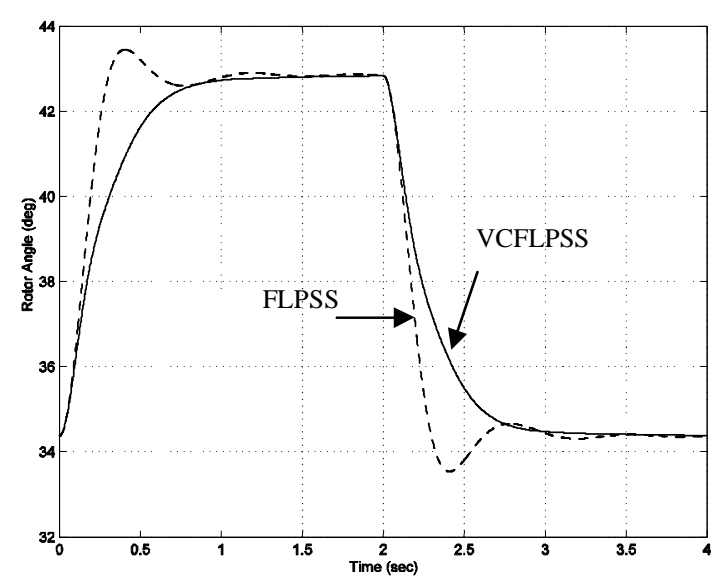

Fig.(10) Time variation in rotor power angle (a) and excitation voltage (b)due to a $10 \%$ increase in $T_{\text {mech }}$; with full recovery after $2 \mathrm{sec}$

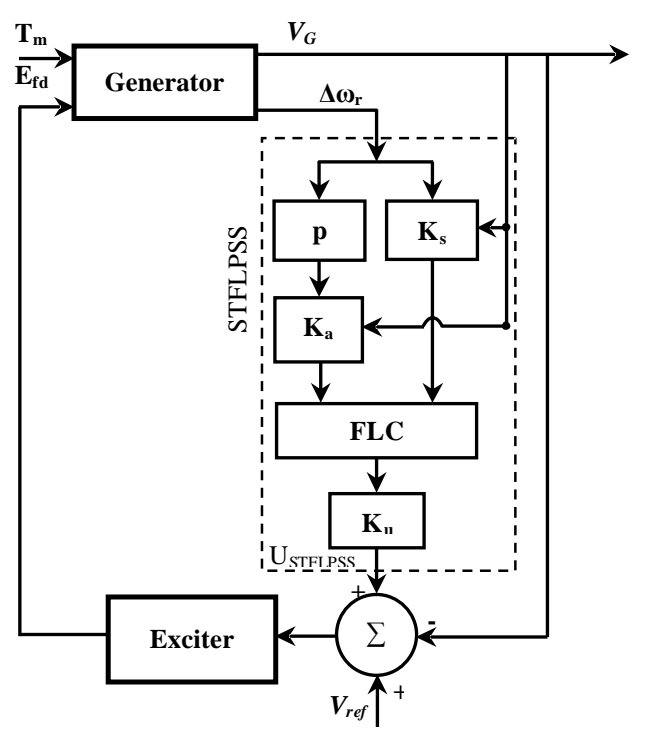

Fig.(9) Block diagram for STFLPSS

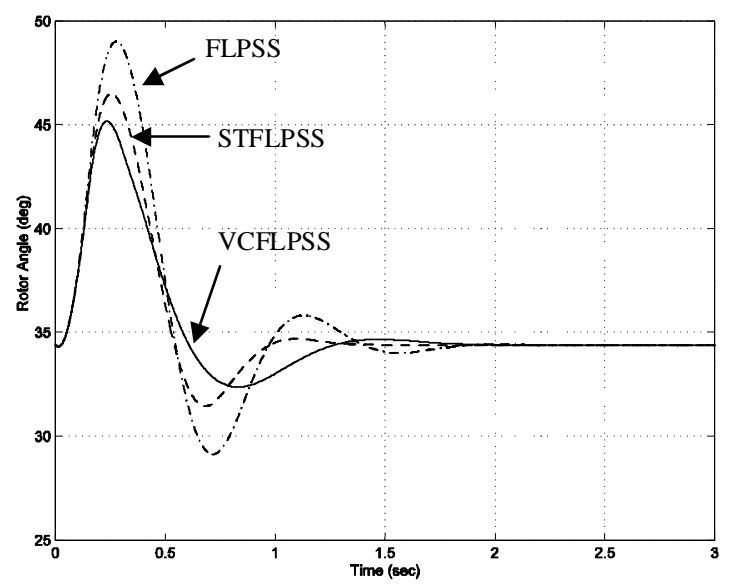

Fig.(11) Time variation in rotor power angle(a) and excitation voltage $(b)$ due to a three-phase short circuit at the HT terminals of the power transformer with system restored after a $150 \mathrm{msec}$ 
The adoption of fuzzy logic technique to the power system stabilizer operation has noticeably enhanced the performance of the voltage control system. In fig.(8) and fig.(9) the block diagrams of the voltage controlled fuzzy logic power system stabilizers (VCFLPSS) and the self tuned fuzzy logic power system stabilizer (STFLPSS) respectively are presented. The performance of both VCLFPSS and STFLPSS are presented in fig.(10) when the system undergoing a small disturbance and in fig.(11) when the system is subjected to a severe three-phase short circuit with a fault duration of $150 \mathrm{msec}$. The use of STFLPSS has expanded the system stability limit to withstand a fault duration of $432.5 \mathrm{msec}$, while the figure was limited to $346 \mathrm{msec}$ with the conventional (VCPSS) delivering an increase in the transient stability limit by $25 \%$ over the (VCPSS).

\section{Selection and Conditioning of the Supplementary Signal (Control of the Self Excited Oscillations)}

The concept of self excited oscillations is related to the low X/R ratio in tie line interconnecting a plant to the remaining part of the system $[8,17]$. This form of instability causes the occurrence of electrical oscillations thereby generating mechanical oscillatory torques. Various approaches to the prevention of the self excited oscillation were, earlier, suggested such as line filters, by pass filters or attempting to control the phenomena using static VAR compensators, excitation voltage control, and reactive power switching [17]. To date all these measures have proven to produce limited damping on this form of instability. The concept of using field control with reactive power as supplementary signal termed negative damping stabilizers, NDS, has produced encouraging results [17]. The adoption of GAs approach, to decide for the optimum controller's parameters, has boosted the efficacy of the NDS controller [18]. The power system adopted for the study is given in fig.(2). The system data and controllers parameter are given in Appendix B. The time variation in reactive power picture in the post-disturbance period is shown in fig.(12.a) and fig.(12.b) for both small and large perturbations. The build up of self excited oscillations is quite clear.

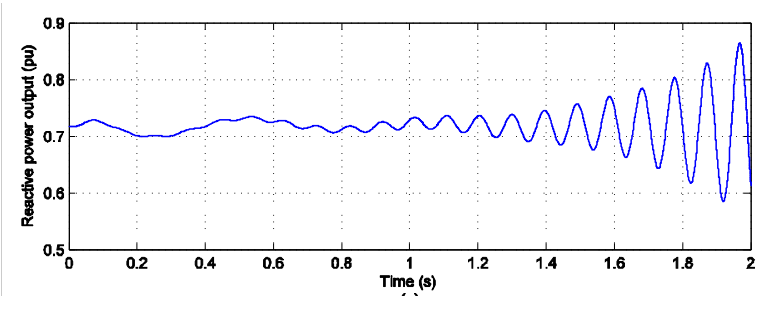

Fig.(12.a) Reactive power output when system is subjected to $10 \%$ reduction in Tmech for $100 \mathrm{msec}$

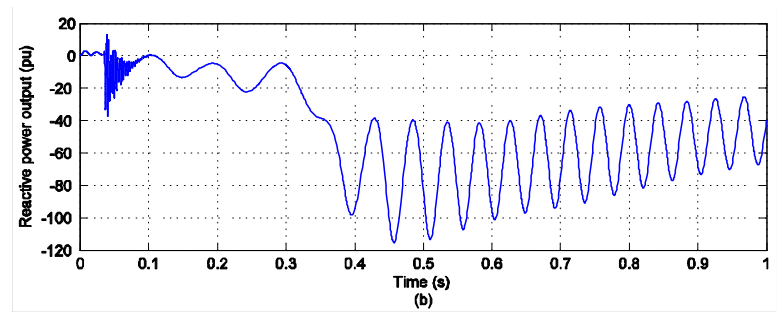

Fig.(12.b) Reactive power output when system is subjected to $10 \%$ reduction in Tmech for $100 \mathrm{msec}$ 


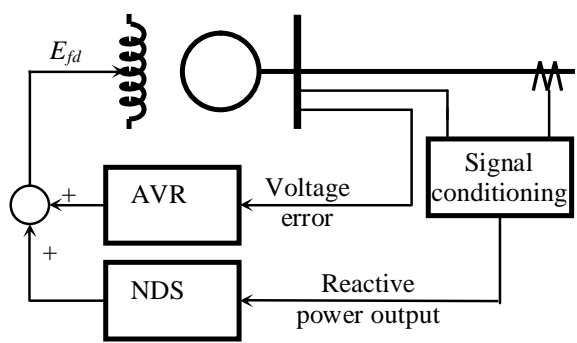

(a)

Full excitation system

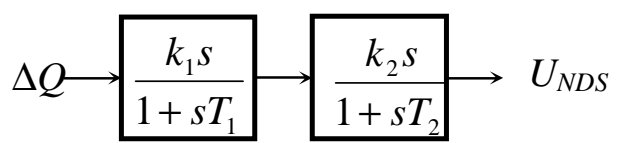

(b)

Fig.(13) Negative damping stabilizer

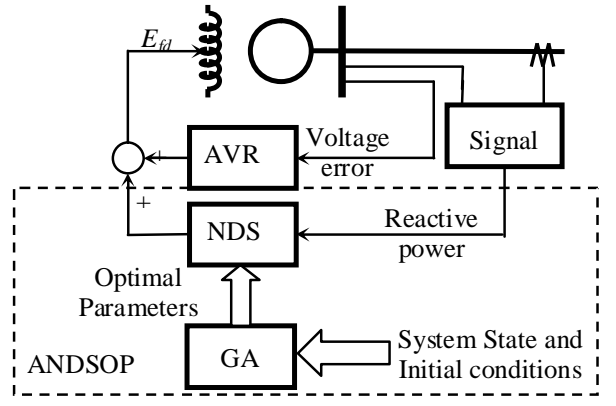

(a)

Full excitation system with GA parameter optimization

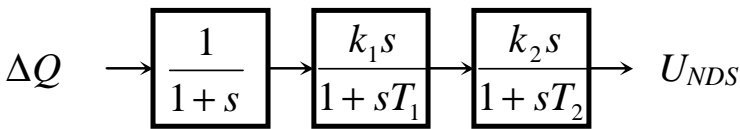

(b)

Fig.(14) ANDSOP controller transfer function

In fig.(13) the block diagram of a conventional negative damping stabilizer (NDS) is presented; while fig.(14) shows the functional diagram of an adaptive NDS with computed optimal parameters using GAs.

Table I Eigenvalues for systems B with $90 \%$ compensation level and different voltage control supplementary signal

\begin{tabular}{|c|c|c|c|c|c|c|}
\hline \multicolumn{3}{|c|}{ Modes } & $\begin{array}{l}\text { Constant } \\
\text { Excitation }\end{array}$ & $\begin{array}{l}\text { Fast Acting } \\
\text { Static } \\
\text { Exciter }\end{array}$ & $\begin{array}{c}\text { Exciter with } \\
\text { NDS }\end{array}$ & $\begin{array}{c}\text { Exciter } \\
\text { with } \\
\text { ANDSOP }\end{array}$ \\
\hline \multirow{4}{*}{ 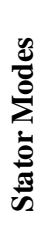 } & \multicolumn{2}{|c|}{ Network Modes $\left(\omega_{\text {sync }}+\omega_{\text {n1 }}\right)$} & $-6.3193 \pm \mathrm{j} 2607$ & $-5.9334 \pm \mathrm{j} 2607.8$ & $-5.9334 \pm \mathrm{j} 2607.8$ & $-5.9324 \pm \mathrm{j} 2607.9$ \\
\hline & \multicolumn{2}{|c|}{ Network Modes $\left(\omega_{\text {sync }}+\omega_{\text {n1 } 1}\right)$} & $-8.0104 \pm \mathrm{j} 1852.6$ & $-7.2143 \pm \mathrm{j} 1851.1$ & $-7.2143 \pm \mathrm{j} 1851.1$ & $-7.3323 \pm \mathrm{j} 1851.1$ \\
\hline & \multicolumn{2}{|c|}{ Electrical Mode $\left(\omega_{\text {sync }}+\omega_{\mathrm{n} 2}\right)$} & $-4.1568 \pm j 688.05$ & $-4.1276 \pm j 688.13$ & $-3.3882 \pm j 687.9$ & $-4.1103 \pm \mathrm{j} 688.17$ \\
\hline & \multicolumn{2}{|c|}{ Electrical Mode $\left(\omega_{\text {sync }}-\omega_{\mathrm{n} 2}\right)$} & $+3.0308 \pm \mathrm{j} 65.894$ & $+0.75664 \pm \mathrm{j} 71.601$ & $-6.6615 \pm j 73.027$ & $-1.584 \pm \mathrm{j} 64.712$ \\
\hline \multirow{4}{*}{$\begin{array}{l}\frac{8}{0} \\
\sum_{0}^{0} \\
\vdots \\
\stackrel{0}{0}\end{array}$} & 远 & Hunting Mode & $-1.7551 \pm \mathrm{j} 11.672$ & $-1.4271 \pm \mathrm{j} 11.505$ & $-1.545 \pm \mathrm{j} 11.533$ & $-2.0486 \pm \mathrm{j} 11.121$ \\
\hline & \multirow{3}{*}{ 莺 } & $\begin{array}{l}\text { Field \& Control } \\
\text { Mode }\end{array}$ & -0.36144 & $-23.3 \pm \mathrm{j} 26.11$ & $\begin{array}{l}-10.329 \pm \mathrm{j} 37.238 \\
-57.671 \\
-18.021 \\
\end{array}$ & $\begin{array}{l}-11.273 \pm \mathrm{j} 49.068 \\
-1.584 \pm \mathrm{j} 0.5251 \\
-42.854\end{array}$ \\
\hline & & D-axis Mode & -33.58 & -90.423 & -92.319 & -90.943 \\
\hline & & Q-axis Mode & -16.965 & -14.008 & -12.715 & -15.809 \\
\hline
\end{tabular}

Using the eigenvalue analysis technique, a comparison is made between the system characteristic roots when undergoing small disturbance encompassing the following voltage control cases: absence of any control action, control with fast acting exciter, conventional negative damping stabilizer excitation and finally the adaptive negative 
damping stabilizer with optimum parameters at a level of series compensation of $90 \%$, where the system is in deep instability, the results obtained in table I show that the simple excitation system failed to stabilize this phenomena.

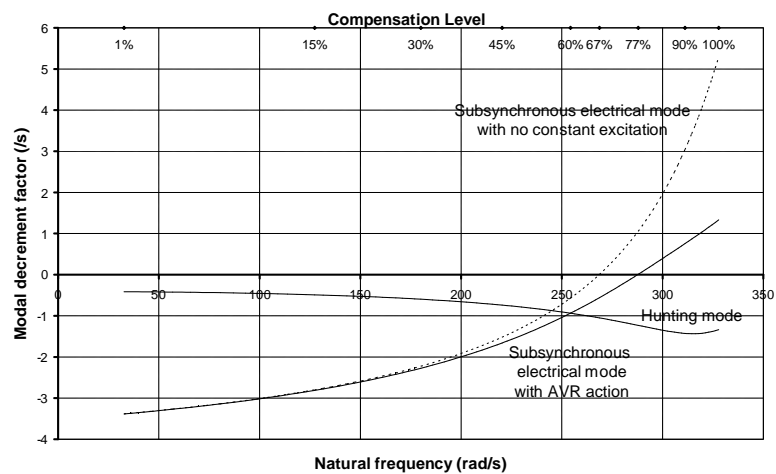

Fig.(15) Locus of the $\left(\omega_{\text {sync }}-\omega_{n}\right)$ mode for values of $0.1<x_{c}<1$ with no control and with conventional Fast acting AVR control

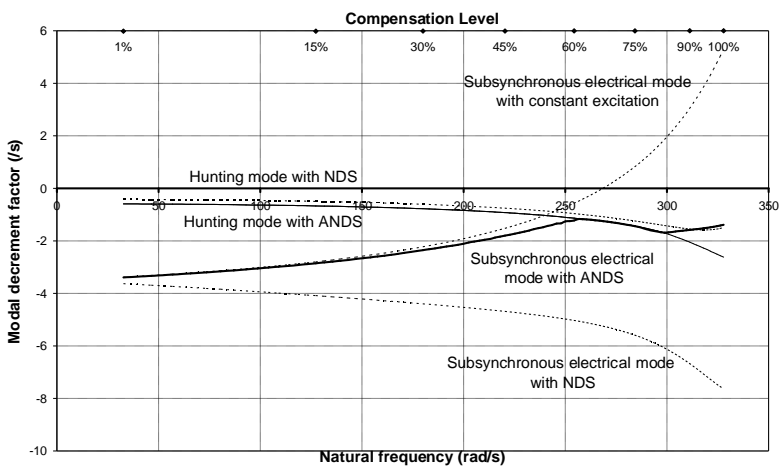

Fig.(16) Locus of the $\left(\omega_{\text {sync }}-\omega_{n}\right)$ mode for values of $0.1<x_{c}<1$ with NDS and ANDSOP control

The small perturbation model of the adopted power system was repeatedly solved for values of $1 \%<x_{c}<100 \%$ of the line series reactance and locus of the damping of the electrical mode and hunting mode are plotted in fig.(15) against the resulting natural angular frequency for the cases of constant excitation and conventional AVR. The results obtained exhibit self excited oscillation instability. Similarly in fig.(16) with NDS and ANDSOP where system stability was maintained over the range of compensation. Furthermore, in fig.(17) and fig.(18) system suffered into instability except for the case of ANDSOP controller.
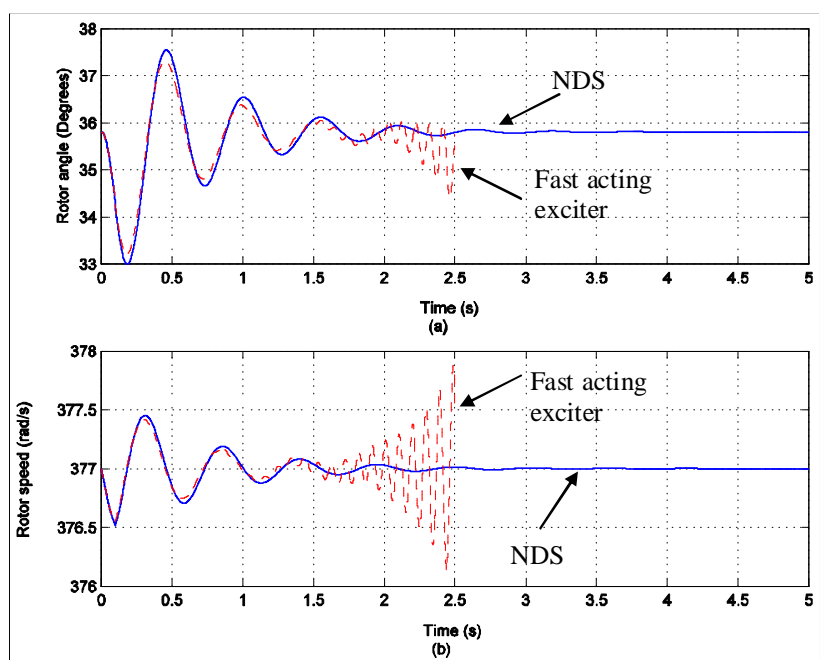

Fig.(17) Time variation in rotor angle and angular speed due to a $10 \%$ reduction in $T_{\text {mech }}$ for 100 msec at $90 \%$ compensation level
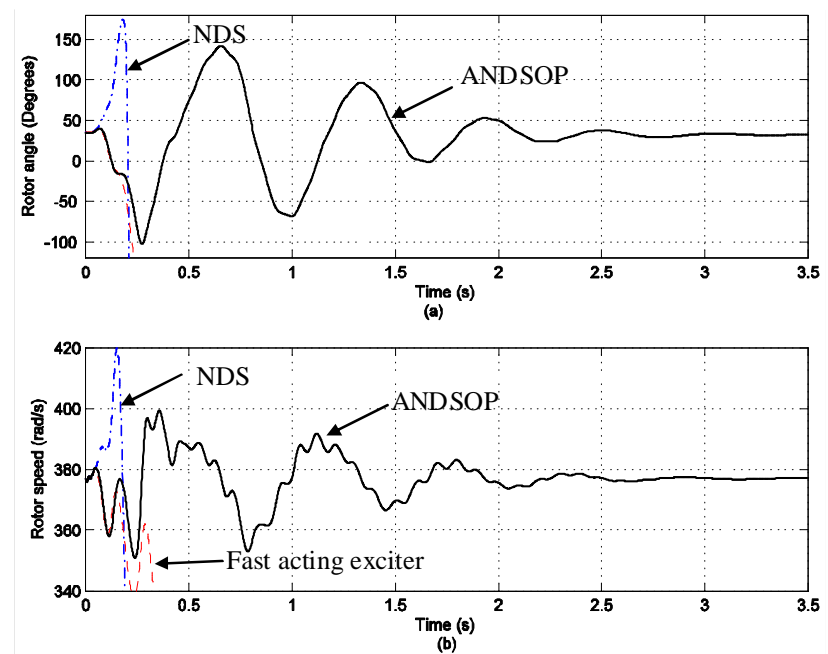

Fig.(18)Time variation in rotor angle and angular speed due to a $3 \phi$-short circuit at the high tension side of the power transformer for a period of $35 \mathrm{msec}$ at $90 \%$ compensation level 


\section{Selection and Conditioning of the Supplementary Signal (Control of the Subsynchronous Resonance Phenomena)}

In a power system with series compensated lines the electrical system will exhibit oscillations at its natural frequency, as the level of compensation is usually in the vicinity of $80 \%$ of the line series inductance. Thus an electrical oscillatory mode will develop at side band frequencies $\left(\omega_{\text {sync }}+\omega_{n}\right)$ and $\left(\omega_{\text {sync }}-\omega_{n}\right)$ the latter obviously fall in the subsynchronous range and may coincide with one or more of the mechanical natural modes causing electromechanical instability leading to material fatigue and eventually to shaft failure. This is referred to subsynchronous resonance phenomena $[10,19]$.

In fig.(19) the shaft mode shapes of the four masses turbine generator rotor are presented where there basic mechanical natural frequency are 308.5, 209.2, 127.9 and $9.75 \mathrm{rad} / \mathrm{sec}$. Referring to the dotted line box the low pressure turbine and generator rotor masses maintained an antiphase swinging relation in the mode 3 , mode 2 and mode 1; thus the difference between the angular speed of this masses will be taken as the supplementary signal to be fed to the excitation system through the usual PSS lead/lag function and the control thus formed is termed the modified power system stabilizer

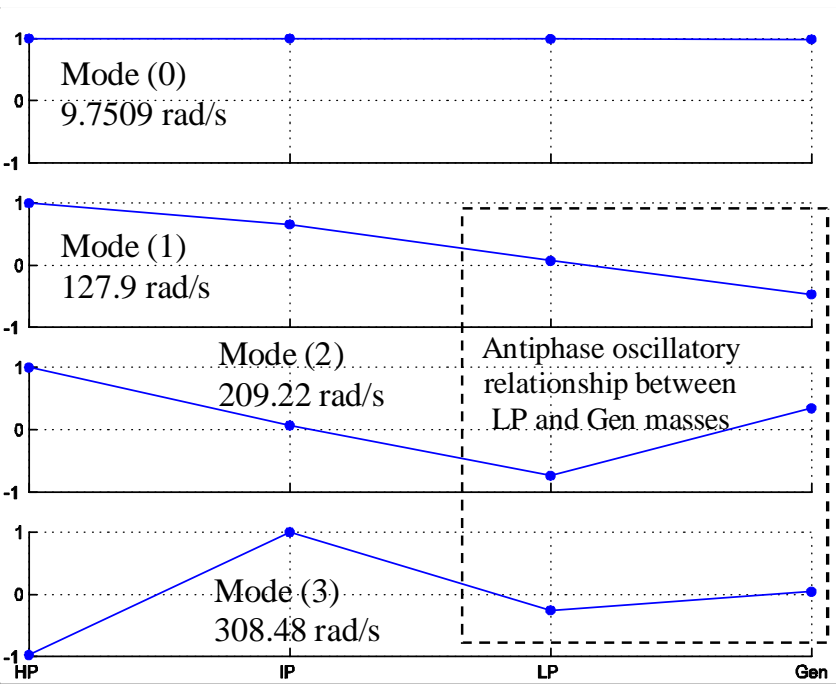

Fig.(19) Mechanical mode shapes and natural frequencies (MPSS).

Mechanical modes with natural frequency near the synchronous speed are normally stable, as they belong to a mechanical mode shape where all rotor masses are oscillating in antiphase to each other at an angular frequency of $308.48 \mathrm{rad} / \mathrm{sec}$. On the other hand mechanical modes in the mid range of the subsynchronous domain are characterised by a group of masses oscillating against each other producing either one point of torsional location (mode1) or two points of torsional locations (mode 2) along the length of the shaft. Mechanical modes in this range of oscillation are prone to instability and are usually subjected to encounter the subsynchronous resonance phenomena.

At lower range of subsynchronous oscillations all rotor masses will swing in unison against the mass of the infinite system, this mode is referred to as mode 0 or hunting mode and usually exhibits poor damping and may cause machine fall out of synchronism. 
Unlike the situation with conventional PSS controllers, where the supplementary signal is derived from the generator rotor angular speed deviation from the synchronous angular speed, the idea behind the suggested modified PSS controller as previously mentioned resides in selecting its supplementary signal to be proportional to the angular speed difference between the rotor mass and the antecedent low pressure turbine mass. The excitation system with the proposed modified PSS (MPSS) transfer function are shown in fig.(20). The supplementary signal loop consists of a two stage high-pass filters to ensure that

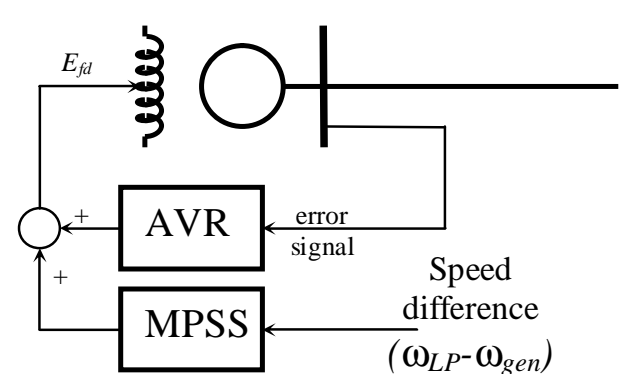

(a)

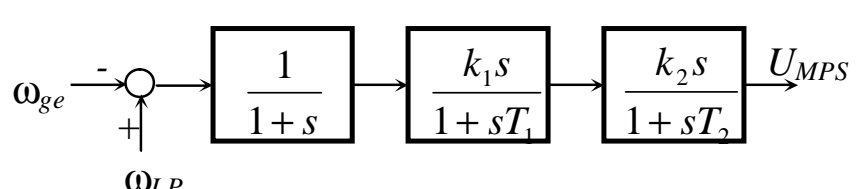

(b)

Fig.(20) Generator with AVR and MPSS (a) Full system block diagram

(b) Suggestion MPSS transfer function the controller will not affect the machine hunting mode and a single stage low-pass filter to block the supersynchronous frequency components of the input signal. The output of the proposed controller is fed directly to the AVR output rather than the voltage error in the normal PSS.

The small perturbation model of the power system shown in fig.(3) and system data and controller parameters are given in Appendix B was developed and repeatedly solved using the eigenvalue technique for values of line series compensation in the range of $1 \%<\mathrm{x}_{\mathrm{cs}}<100 \%$ of the line series reactance and the results obtained at $\mathrm{x}_{\mathrm{cs}}$ equal $26 \%$ of line series compensation where the coincidence between the electrical mode $\left(\omega_{\text {sync }}-\omega_{n}\right)$ and the mechanical mode 2 is presented with various excitation models in table II. Similarly the coincidence between the electrical mode $\left(\omega_{\text {sync }}-\omega_{n}\right)$ and the mechanical mode 1 at $\mathrm{x}_{\mathrm{cs}}$ equal to $58 \%$ of series compensation are shown in table III.

Also the effect of the conventional PSS was successful in controlling the instability at the mechanical mode 2 when undergoing a small perturbation; yet it failed to do so at the coincidence frequency with mode 1 . Evidently, the damping introduced by the MPSS controller has maintained all mechanical mode stable over the full range of variation in $\mathrm{x}_{\mathrm{cs}}$. 
Table II Eigenvalues for the power system with $26 \%$ series compensation

\begin{tabular}{|c|c|c|c|c|}
\hline & & & \multicolumn{2}{|c|}{ Excitation Control } \\
\hline & Mode & $\begin{array}{c}\text { Constant Excitation } \\
\text { (No Control) }\end{array}$ & PSS & MPSS \\
\hline \multirow{4}{*}{ 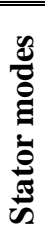 } & Network $\operatorname{Modes}\left(\omega_{\text {sync }}+\omega_{\mathrm{n} 1}\right)$ & $-6.3409 \pm j 2602.1$ & $-6.05 \pm \mathrm{j} 2603.4$ & $-6.0571 \pm j 2603.4$ \\
\hline & Network $\operatorname{Modes}\left(\omega_{\mathrm{sync}}-\omega_{\mathrm{n} 1}\right)$ & $-8.0511 \pm \mathrm{j} 1847.8$ & $-7.3884 \pm \mathrm{j} 1845.3$ & $-7.4024 \pm j 1845.4$ \\
\hline & Electrical mode $\left(\omega_{\mathrm{sync}}+\omega_{\mathrm{n} 2}\right)$ & $-3.9461 \pm j 544.58$ & $-3.9348 \pm j 544.61$ & $-3.9602 \pm \mathrm{j} 544.5$ \\
\hline & Electrical mode $\left(\omega_{\mathrm{sync}}-\omega_{\mathrm{n} 2}\right)$ & $-4.4431 \pm \mathrm{j} 209.12$ & $-3.0213 \pm j 211.41$ & $-2.9201 \pm \mathrm{j} 198.49$ \\
\hline \multirow{7}{*}{ 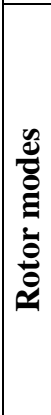 } & Mechanical mode (3) & $-1.2923 \pm j 308.84$ & $-1.2934 \pm \mathrm{j} 308.84$ & $-1.3097 \pm \mathrm{j} 308.87$ \\
\hline & Mechanical mode (2) & $1.4666 \pm \mathrm{j} 209.07$ & $-0.25257 \pm \mathrm{j} 207.64$ & $-1.0 \pm \mathrm{j} 220.84$ \\
\hline & Mechanical mode (1) & $-0.36223 \pm j 128.12$ & $-0.25265 \pm \mathrm{j} 127.06$ & $-4.9705 \pm j 123.89$ \\
\hline & Mechanical mode (0) & $-0.6814 \pm j 10.208$ & $-0.25256 \pm \mathrm{j} 10.858$ & $-1.0 \pm \mathrm{j} 10.234$ \\
\hline & Excitation system modes & -0.25518 & $\begin{array}{c}-29.607 \pm \mathrm{j} 51.657 \\
-61.139 \\
-0.28845 \\
-0.25257\end{array}$ & $\begin{array}{c}-19.315 \pm \mathrm{j} 54.633 \\
-25.38 \\
-5.7935 \\
-1.0\end{array}$ \\
\hline & D- axis damper mode & -32.241 & -77.986 & -81.626 \\
\hline & Q-axis damper mode & -10.033 & -9.7479 & -10.018 \\
\hline
\end{tabular}

Table III Eigenvalues for the power system with $58 \%$ series compensation

\begin{tabular}{|c|c|c|c|c|}
\hline & \multirow[b]{2}{*}{ Mode } & \multirow[b]{2}{*}{$\begin{array}{c}\text { Constant Excitation } \\
\text { (No Control) }\end{array}$} & \multicolumn{2}{|c|}{ Excitation Control } \\
\hline & & & PSS & MPSS \\
\hline \multirow{4}{*}{ 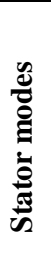 } & Network $\operatorname{Modes}\left(\omega_{\mathrm{sync}}+\omega_{\mathrm{n} 1}\right)$ & $-6.3302 \pm \mathrm{j} 2604.5$ & $-5.9964 \pm j 2605.6$ & $-5.9995 \pm \mathrm{j} 2605.6$ \\
\hline & Network $\operatorname{Modes}\left(\omega_{\text {sync }}-\omega_{\mathrm{n} 1}\right)$ & $-8.0307 \pm \mathrm{j} 1850.2$ & $-7.3089 \pm \mathrm{j} 1848.2$ & $-7.3167 \pm \mathrm{j} 1848.2$ \\
\hline & Electrical mode $\left(\omega_{\text {sync }}+\omega_{\mathrm{n} 2}\right)$ & $-4.0768 \pm j 627.01$ & $-4.0601 \pm \mathrm{j} 627.08$ & $-4.068 \pm \mathrm{j} 627.05$ \\
\hline & Electrical mode $\left(\omega_{\text {sync }}-\omega_{\mathrm{n} 2}\right)$ & $-6.209 \pm j 127.28$ & $-2.8387 \pm j 130.76$ & $-1.4337 \pm j 113.62$ \\
\hline \multirow{7}{*}{ 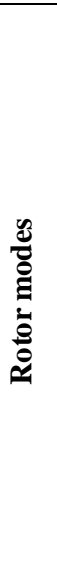 } & Mechanical mode (3) & $-1.2923 \pm \mathrm{j} 308.84$ & $-1.2927 \pm \mathrm{j} 308.84$ & $-1.3013 \pm \mathrm{j} 308.85$ \\
\hline & Mechanical mode (2) & $-0.57249 \pm j 209.06$ & $-0.62454 \pm j 209.12$ & $-1.0201 \pm \mathrm{j} 209.97$ \\
\hline & Mechanical mode (1) & $5.1014 \pm j 127.29$ & $1.2535 \pm \mathrm{j} 125.49$ & $-1.0955 \pm \mathrm{j} 138.33$ \\
\hline & Mechanical mode (0) & $-1.0346 \pm \mathrm{j} 11.054$ & $-0.2535 \pm \mathrm{j} 10.28$ & $-1.2015 \pm \mathrm{j} 11.226$ \\
\hline & Excitation system modes & -0.2909 & $\begin{array}{c}-27.514 \pm \mathrm{j} 42.15 \\
-0.55151 \pm \mathrm{j} 0.2423 \\
-0.15624\end{array}$ & $\begin{array}{c}-23.174 \pm \mathrm{j} 44.998 \\
-47.202 \\
-1.1438 \\
-1.0001 \\
\end{array}$ \\
\hline & D- axis damper mode & -32.717 & -85.269 & -85.589 \\
\hline & Q-axis damper mode & -11.932 & -11.705 & -11.399 \\
\hline
\end{tabular}



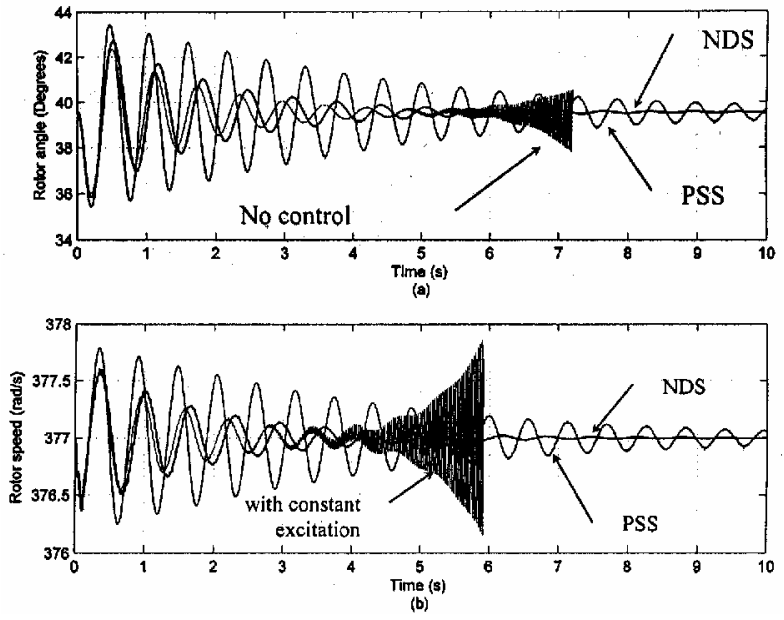

Fig.(21) Time variation of the machine rotor angle (a) and angular speed (b) for a $10 \%$ reduction in $T_{\text {mech }}$ at $26 \%$ compen sation level and system restored after 100 msec for the cases of constant excitation, PSS and NDS controllers
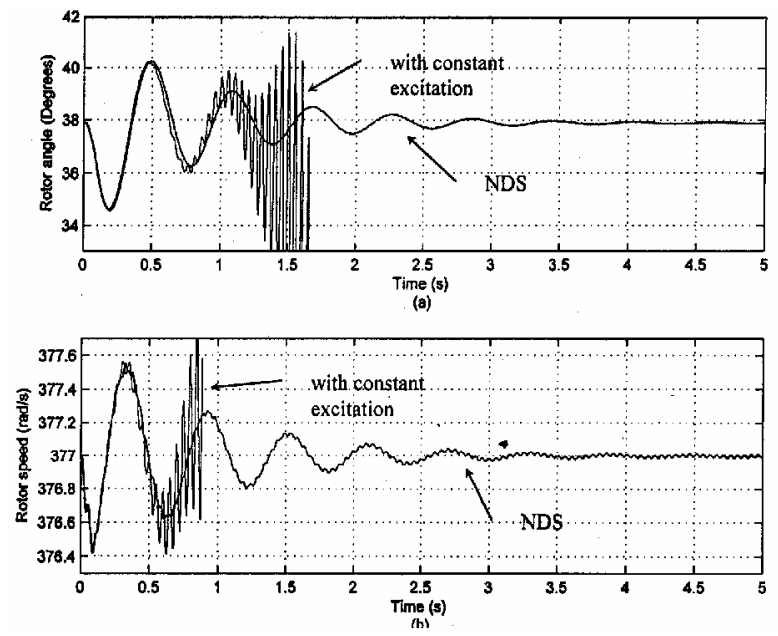

Fig.(22) Time variation of the machine rotor angle (a) and angular speed $(b)$ for a $10 \%$ reduction in $T_{\text {mech }}$ at $58 \%$ compensation level and system restored after 100 msec for the cases of constant excitation and NDS controller
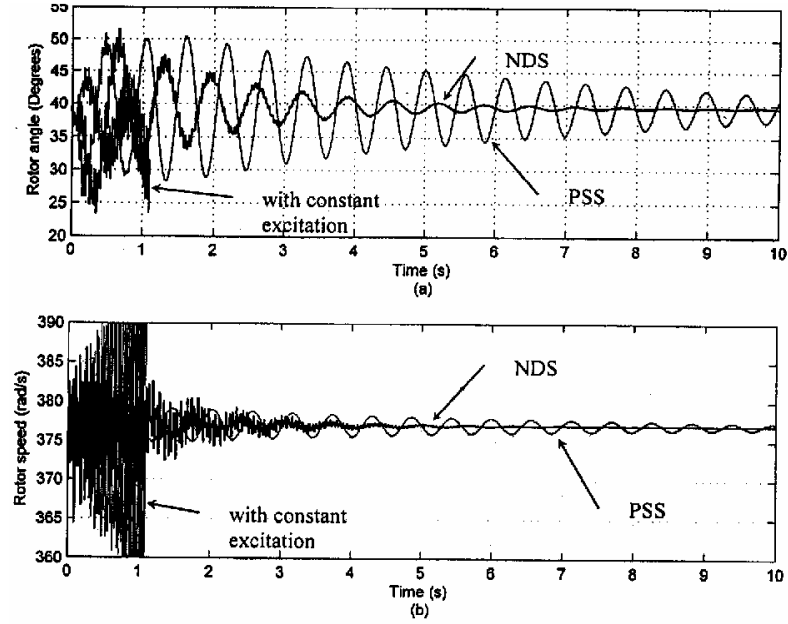

Fig.(23) Time variation of the machine rotor angle (a) and angular speed (b) for a three-phase short circuit at $26 \%$ compensation with system regaining its original state after $80 \mathrm{msec}$ for the cases of constant excitation, PSS and NDS controllers
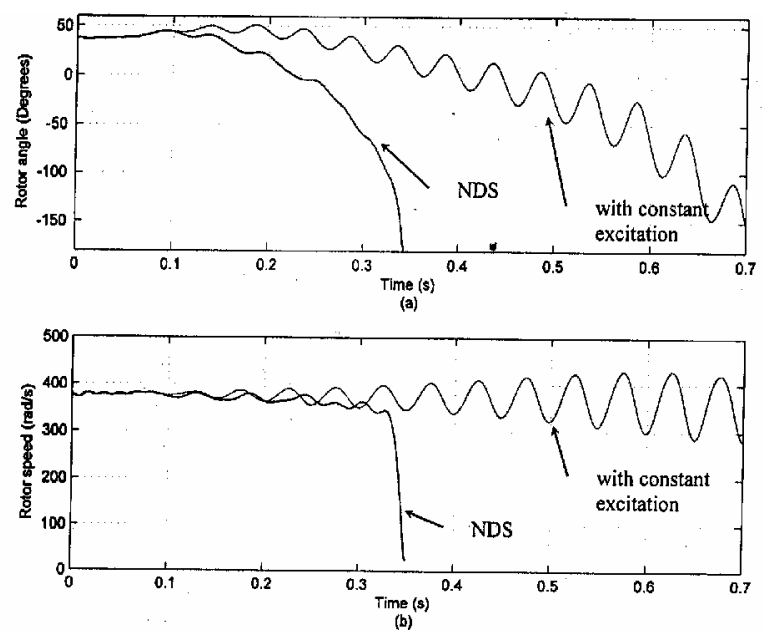

Fig.(24) Time variation of the machine rotor angle (a) and angular speed (b) for a three-phase short circuit at $58 \%$ compensation with system regaining its original state after 80 msec for the cases of constant excitation and NDS controller

The set of results presented in fig.(21) and fig.(22) confirm the potential of the NDS over the PSS as far as the case of small perturbation is concerned. For the case of large scale disturbance results shown in fig.(23) and fig.(24) subsynchronous oscillation where not properly damped. 

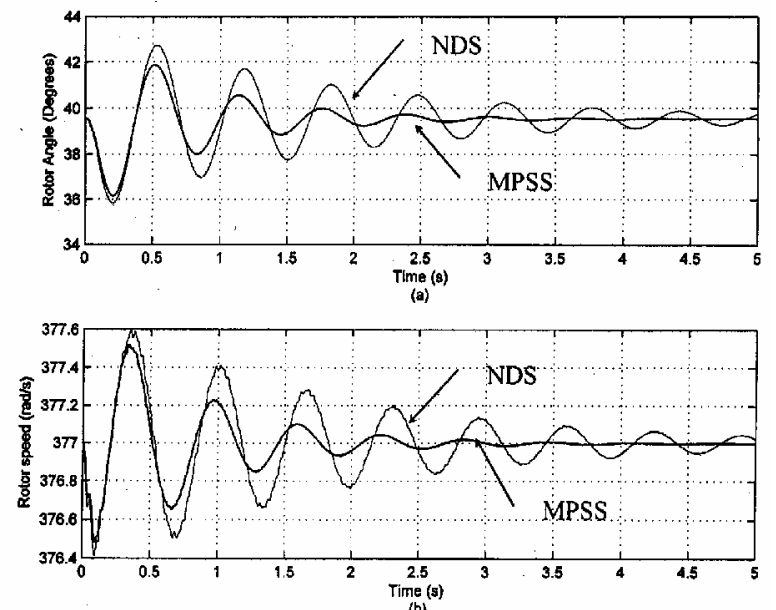

Fig.(25) Time variation of the machine rotor angle (a) and angular speed $(b)$ for a $10 \%$ reduction in $T_{\text {mech }}$ at $26 \%$ compensation level and system restored after 100 msec for the cases of NDS and MPSS controllers
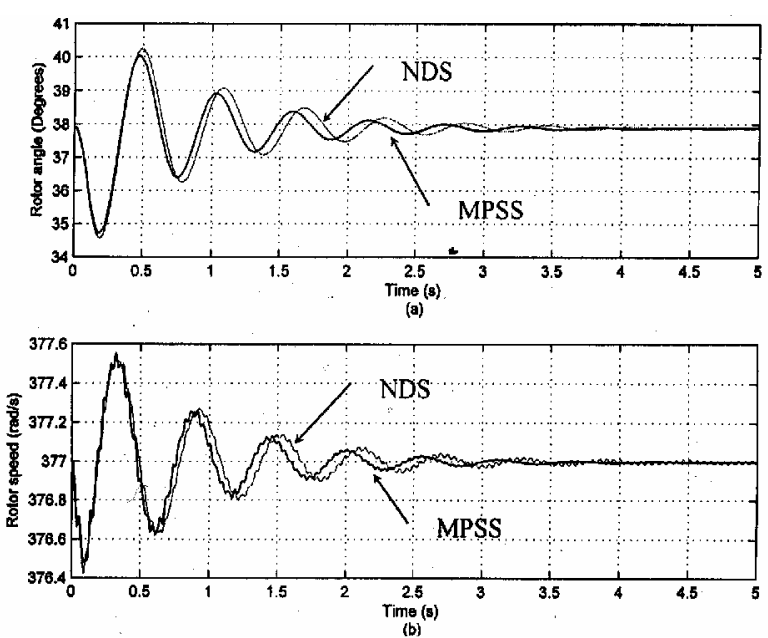

Fig.(26) Time variation of the machine rotor angle (a) and angular speed (b) for a $10 \%$ reduction in $T_{\text {mech }}$ at $58 \%$ compensation level and system restored after 100 msec for the cases of NDS and MPSS controllers
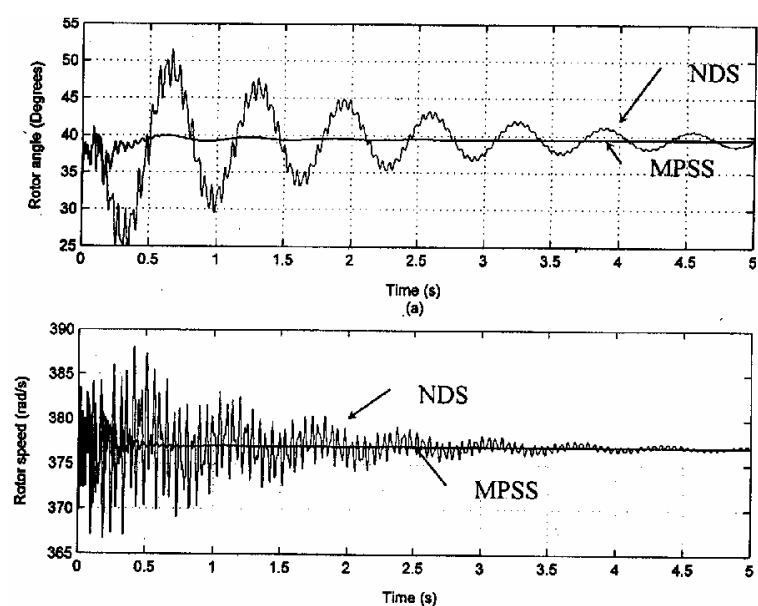

Fig.(27) Time variation of the machine rotor angle (a) and angular speed $(b)$ for a three-phase short circuit at $26 \%$ compensation with system regaining its original state after 80 msec for the cases of NDS and MPSS controllers
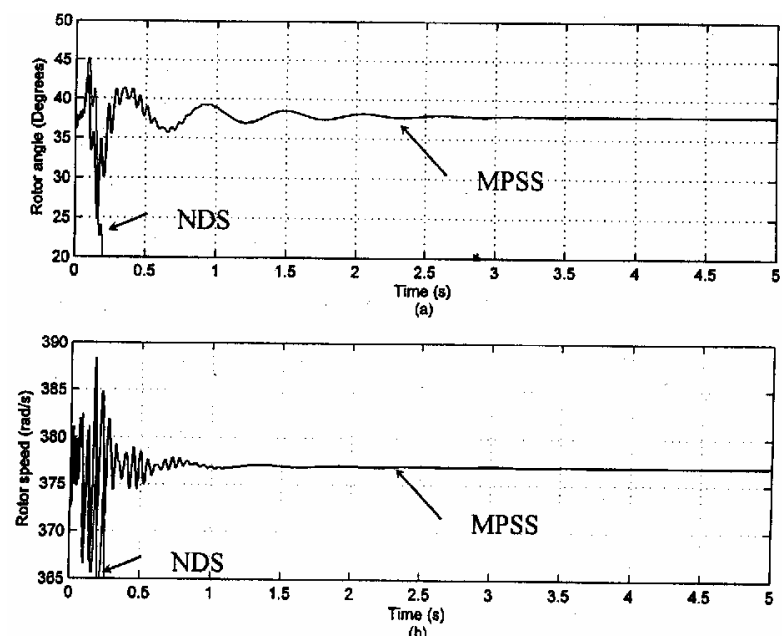

Fig.(28) Time variation of the machine rotor angle (a) and angular speed (b) for a three-phase short circuit at $58 \%$ compensation with system regaining its original state after 80 msec for the cases of NDS and MPSS controllers

From fig.(25), fig.(26), fig.(27) and fig.(28) where the system was subjected to both a small perturbation and a large scale disturbance only the MPSS controller did maintain system stability under both cases of compensation at $\mathrm{x}_{\mathrm{cs}}=26 \%$ and $\mathrm{x}_{\mathrm{cs}}=58 \%$. 


\section{Conclusion:}

- A set of MATLAB algorithms was developed to identify the particular type of the most effective supplementary signal to be introduced to the excitation system to damp out the specific power system mode of instability.

- Through these algorithms, it was made possible the selection and conditioning of the supplementary signals to control the self excited oscillation, the subsynchronous resonance and to expand the power angle stability limit.

- Through selecting the optimum controller parameter, the efficacy of the selected supplementary signal has contributed in enhancing the power angle stability limit.

- For the case of controlling the self excited oscillation it has been demonstrated that the optimal selecting the controlling parameter through adopting the GAs technique did stabilize the self excited oscillation resulting from severe short circuit condition.

- As for subsynchronous resonance phenomena the adequate choice of supplementary signal did stabilize the impertinent subsynchronous resonance oscillation using a modified version of PSS termed here MPSS. This has been achieved through selecting a supplementary signal based on the difference in the angular speed between the low pressure turbine/generator rotor inertias.

- In all the above work a particular signal conditioning strategy was implemented, together with the selection of supplementary signal and optimizing the controller parameters, to suppress the self excited oscillation and to expand the power angle stability limit.

\section{References:}

[1] M. E. Aboul-Ela, A. A. Sallam, J. D. McCally and A. A. Fouad, "Damping Controller Design for Power System Oscillations Using Global Signals", IEEE Transactions on power apparatus and systems, Vol.11, No.2, May 1996.

[2] A. Murdoch., S. Venkataraman, R. A. Lawson and W. R. Pearson, "Integral of acceleration power type PSS Part 1 and Part 2", IEEE Transactions on Power apparatus and systems, Vol. 14, No.4, Dec. 1999 .

[3] El-Metwally, K.A. and Malik, O.P. "Fuzzy logic power system stabilizer",IEE Proc. Gener., Transm., Distrib., Vol. 142, No. 3. May 1995, pp. 277 - 281.

[4] W. Watson and G. Manchur "Experience with Supplementary Damping Signals for Generator Static Exciter System”, IEEE Transaction on Power System Apparatus and Systems, Jun. 1973. 
[5] A.A.Ishak, and M.A.El-Dery, "Enhancing PSS Damping of Generator Rotor Oscillations Using Neuro-Fuzzy Inference System", $7^{\text {th }}$ International Conference on Probabilistic Methods Applied to Power Systems, PMAPS, Sept 22-26,2002 Naples, Italy.

[6] Hassan,. M.A., Malik, O.P. and Hope, G.S. "A fuzzy logic based stabilizer for a synchronous machine', IEEE Trans. Energy Conversion, 1991,6,(3) pp. 407-413.

[7] Takashi Hiyama, Koushi Miyazaki, and Hironori satoh,. “ A Fuzzy Logic Excitation System For Stabilty Enhancement of Power Systems With Multimode Oscillations”, IEEE Transaction on Energy Conversion, Vol. 11, No. 2, June 1996.

[8] H.M.A. Hamdan, F.M.Hughes, "Excitation controller design for the damping of self-excited oscillations in series compensated lines”, IEEE PES Summer Meeting, July 16-21, 1978.

[9] V. Arcidiacono, E. Ferrari, R. Marconato, J. Dos Ghali, D. Grandez, "Evaluation and Improvement of Electromechanical Oscillation Damping by Means of Eigenvalue-Eigenvector Analysis \& practical Results in the central peru power system" IEEE Transactions on Power apparatus and systems, Vol Pas-100, No.1, Jan 1981.

[10] Eli Katz, "Subsynchronous resonance - A 1981 review”, Symposium on countermeasures for subsynchronous resonance, 1981 summer meeting, July 30,1981,pp1-3.

[11] Chin-Hsing Cheng and Yuan-Yih Hsu, "Damping of Generator Oscillations Using an Adaptive Static Var Compensator", IEEE Transactions on Power Systems, Vol.7, No.2, May 1992, pp718-725.

[12] D. C. Lee, R. E. Beaulieu and J. R. Service, "A Power Stabilizer Using Speed and Electrical Power Inputs-Design and Field Experience", IEEE Transactions on power apparatus and systems, Vol. PAS-100, No.9, September 1981.

[13] IEEE Committee Report, "Excitation System Models for Power System Stability Studies", IEEE Transactions on Power Apparatus and Systems, Vol. PAS-100, No.2, February 1981 pp494-508

[14] A.A.Ishak, "A Conceptual Approach to the Analysis of the Modeling Strategies Adopted in Power Systems Stability Studies" "Small Perturbation", The Engineering Research Journal, Shoubra Faculty of Engineering, Zagazig, University, Benha Branch, Cairo, Egypt, January 2005, $\mathrm{N}^{\circ} 3$, pp. 21-38.

[15] A.R. Messina, O. Begovich, M. Nayacbzadeh, "Analytical Investigation of the use of static VAR compensators to aid damping of inter-area oscillations", International Journal of Electrical power \&Energy Systems, Vol 21, no.3, March 1999, pp. 199-210. 
[16] A.A.Ishak and M.S.Helal, "Fuzzy Logic PSS with Voltage Controlled Supplementary Signal for Enhancing Power System Stability ", The Engineering Research Journal, Shoubra Faculty of Engineering, Zagazig University, Benha Branch, Cairo, Egypt, June 2004, Nº1, pp. 78-88.

[17] O.Saito, H.Mukae, and K.Murtoni, "Suppression of Self-Excited Oscillations in SeriesCompensated Transmission Lines by Excitation Control of Synchronous Machines", IEEE Transactions on Power Apparatus and Systems, Vol. PAS-94, No.5, September /October 1975,pp1777-1788.

[18] A.A.Ishak and B.A.Boutros, "Suppression of Self-Excited Oscillations in Power Systems Using Negative Damping Stabilizer with Parameters Optimized by Genetic Algorithms", The Engineering Research Journal, Shoubra Faculty of Engineering, Zagazig University, Benha Branch, Cairo, Egypt, June 2004,Vol.1, PP 66-77.

[19] A.A.Ishak, "Suppression of Subsynchronous Resonance Oscillations in Power Systems Using a Modified PSS", The Engineering Research Journal, Shoubra Faculty of Engineering, Zagazig University, Benha Branch, Cairo, Egypt, October 2004, N², pp. 57-71.

\section{Appendix A:}

1. Generators Data

$$
\begin{aligned}
& R_{a}=0.0029 \quad R_{k q}=0.0073 \quad X_{l a}=0.18 \quad X_{l k q}=0.05 \quad R_{f d}=0.00081 \\
& X_{m d}=1.38 \quad X_{l f d}=0.089 \quad X_{m q}=1.08 \quad R_{k d}=0.0076 \quad X_{l k d}=0.025 \\
& H=2.75 \quad \omega_{o}=377 \mathrm{rad}_{\text {. }} \mathrm{sec}^{-1}
\end{aligned}
$$

2. Transformer and Transmission System Data

$$
R_{t r}=0.008 \quad X_{t r}=0.2 \quad R_{T L}=0.02, \quad X_{T L}=0.2, \quad X_{c p}=10
$$

3. Fast Acting Static Exciter Parameter

$$
K_{E}=400 \quad T_{E}=0.02
$$

4. Conventional Power system Stabilizer Transfer Function

$$
G_{P S S}(s)=17.5 \times \frac{1+0.162 s}{1+0.025 s}
$$

5. Voltage-Controlled Power System Stabilizer Parameters

$$
K v=0.956 \text {. }
$$

6. Fuzzy Logic Controller FLPSS

$$
K_{s}=0.045 \quad K_{a}=0.00165
$$

7. Voltage-Controlled Fuzzy Logic Stabilizer (VCFLPSS)

$$
K v=0.756 \text {. }
$$




\section{Appendix B:}

Data of The Single Machine Infinite Busbar Power System NDS and MPSS controllers

1- System Electrical Data

All data are given in per unit with base voltage of $500 \mathrm{kV}$ and base power of $10 \mathrm{GW}$

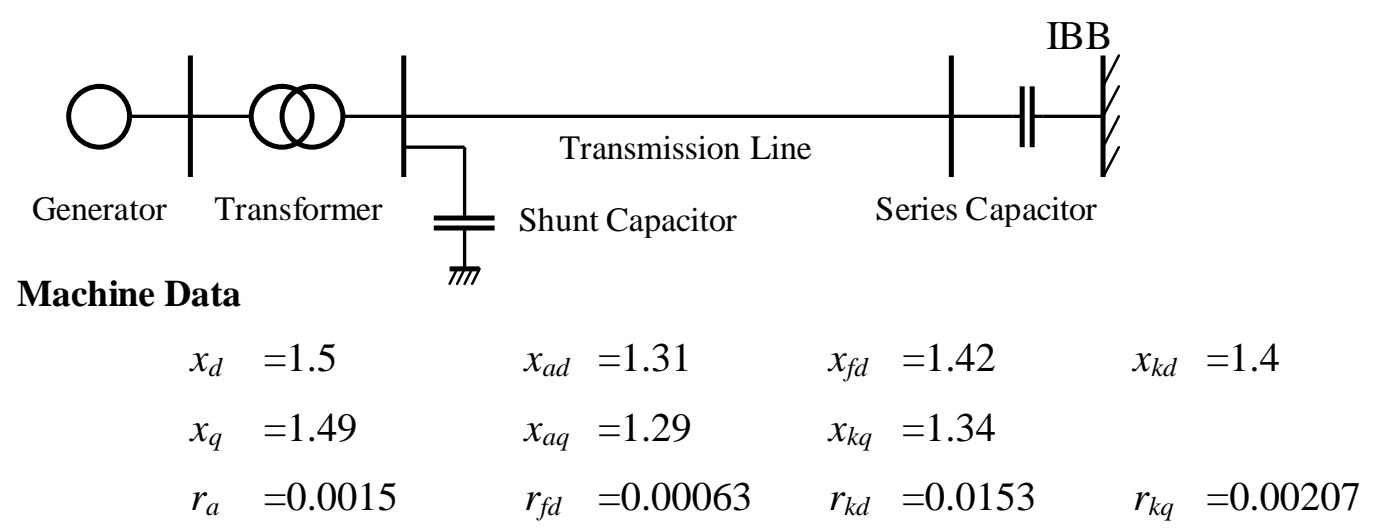

Transformer Data

$$
x_{t r}=0.135 \quad r_{t r}=0.003
$$

Transmission Line Data

$$
x_{t l}=1.205 \quad r_{t l}=0.025 \quad x_{c p}=10 \quad 0.1205<x_{c p}<1.205
$$

Exciter Data

$$
k_{e}=400.0 \quad T_{e}=0.01
$$

System Operating Conditions
$V^{\infty}=1.0$
$P \quad=0.8$
$Q=0.6$
$\omega_{s}=377 \mathrm{rad} / \mathrm{s}$

\section{System Mechanical Data}

2.A. Single Mass Model

$$
H=2.62 \mathrm{~s} \quad D_{m}=1.0
$$

\section{B. Lumped Multi-Mass Shaft Model}

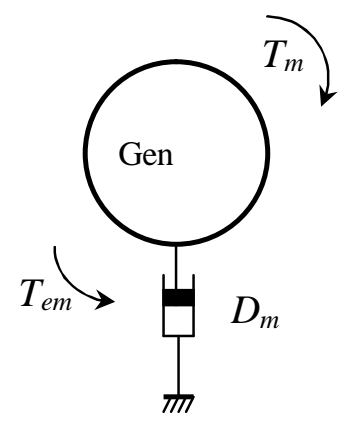

All system data are identical to the system shown in appendix A except for mechanical data given below
$D_{H P}=0.4$
$D_{I P}=0.3$
$D_{L P}=0.3$
$D_{\text {Gen }}=0.0$
$D_{H I}=0.4$
$D_{I L}=0.4$
$D_{L G}=0.4$
$K_{H I}=47.0$
$K_{I L}=61.0$
$K_{L G}=74.0$
$H_{H P}=0.1883 \mathrm{~s}$
$H_{H I P}=0.3351 \mathrm{~s}$
$H_{L P}=0.7562 \mathrm{~s} \quad H_{G e n}=1.0 \mathrm{~s}$ 